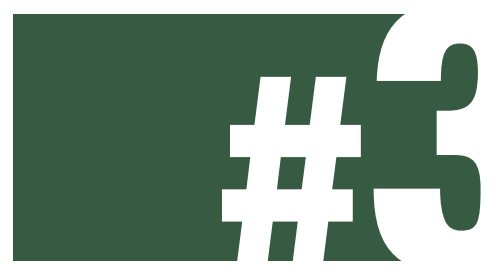

ESPECIAL ÉTICA EM TEMPOS DE CRISE

\title{
A ÉTICA EM TEMPOS DE CRISE
}

A ÉTICA VIVE TEMPOS DE CRISE E ESCÂNDALOS, GERADOS MUITAS VEZES PELA AMBIÇÃO DO CONSUMO E DO PRAZER. O QUE É PRECISO OBSERVAR É QUE NÃO SOMENTE AS UNIVERSIDADES E A FAMÍLIA, MAS TAMBÉM AS EMPRESAS, AGEM COMO CELEIROS PARA FOMENTAR ATITUDES MADURAS E ÍNTEGRAS

MARIA CECILIA COUTINHO DE ARRUDA, professora da FGV-EAESP, maria.cecilia.arruda@fgv.br

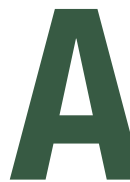

crise econômica e financeira que assola o mundo atual sugere uma reflexão importante para todos sobre princípios e valores culturais e éticos que sustentam a convivência humana. A iniciativa privada não consegue abarcar todos os setores da economia, todos os produtos e serviços de que a sociedade necessita. O papel do Estado permanece essencial na solução de problemas em áreas como infraestrutura, educação e saúde, atendimento a pessoas idosas ou portadoras de deficiência, entre muitas outras. É fundamental uma complementaridade entre o setor público e o setor privado em uma economia de mercado. No limite da liberdade econômica, o liberalismo poderia deixar de lado preocupações sociais sérias, em nome do lucro.

O que teria gerado essa crise? São muitas as causas ou interpretações, sendo difícil identificá-las isoladamente. Erros nas políticas financeiras e econômicas? Fragilidade estrutural das instituições políticas, econômicas e financeiras? Afastamento da ética no conserto de uma economia mundial pautada pelo egoísmo, pelo materialis- 
mo e pelo utilitarismo? Erros técnicos (im)previsíveis? Falta de responsabilidade moral? Bolha especulativa sobre crédito e imóveis? Excesso de confiança nos produtores, empresários, investidores e consumidores? Descompasso entre geração de renda e crescimento financeiro, consumo e especulação?

\section{ÉTICA E DEMOCRACIA}

Desde que exista ética, a iniciativa privada pode buscar solução para muitas necessidades humanas. Quanto mais democrático for o Estado, mais fácil será conseguir que a atividade lucrativa seja desenvolvida dentro de padrões morais. Os legisladores estabelecerão limites para que o bem-estar social prevaleça sobre interesses privados escusos. Daí dizer-se que onde a ética melhor se aclimata é no regime democrático.

$\mathrm{O}$ cidadão que se vê tratado como pessoa, e não como simples indivíduo, tende a agir com liberdade, e isso é fundamental para a economia de mercado. A convicção de que ele pode escolher os bens e serviços de que necessita reduz a sensação de insegurança. Esse cidadão transforma-se livremente em consumidor dos bens, serviços e ideias que entende serem necessários para seu bem-estar. Ocorre uma mudança gradual de mentalidade que o faz valorizar a vida de outra maneira.

\section{INCENTIVO ÉTICO AO CONSUMO}

Melhores condições de consumo e bem-estar, ainda que, por vezes, ocorram somente no nível subconsciente, tornam as pessoas mais felizes e satisfeitas. Essa é a meta importante, tanto para os governos quanto para os empreendedores da iniciativa privada. Embora a meta da economia seja o consumo, o sentido da vida não se resume aos bens da racionalidade econômico-material que satisfazem o exterior. O estímulo e o respeito a uma vida interiormente edificante levam ao seu sentido completo, aos valores de caráter universal que conduzem o cidadão - consumidor, do ponto de vista econômico - ao seu caminho adequado.

À medida que aumenta o bem-estar, parece que muita importância vai sendo atribuída aos valores do prazer, especialmente material, que levam à superficialidade. Se essa relação de causalidade for real e objetiva, o desenvolvimento econômico deve ser acompanhado de boa formação moral. À medida que mais assalariados se incorporam ao mercado, mais produtos e serviços são adquiridos. Ao se estabelecerem novos padrões e estilos de vida, uma hierarquia de valores deve ser considerada no planejamento do consumo. Uma educação para o consumo ajudaria a identificar a proporção ideal de bens (imediatos e duradouros) e serviços a serem adquiridos. A passagem da pobreza ao bem-estar pode acarretar uma visão materialista da vida 


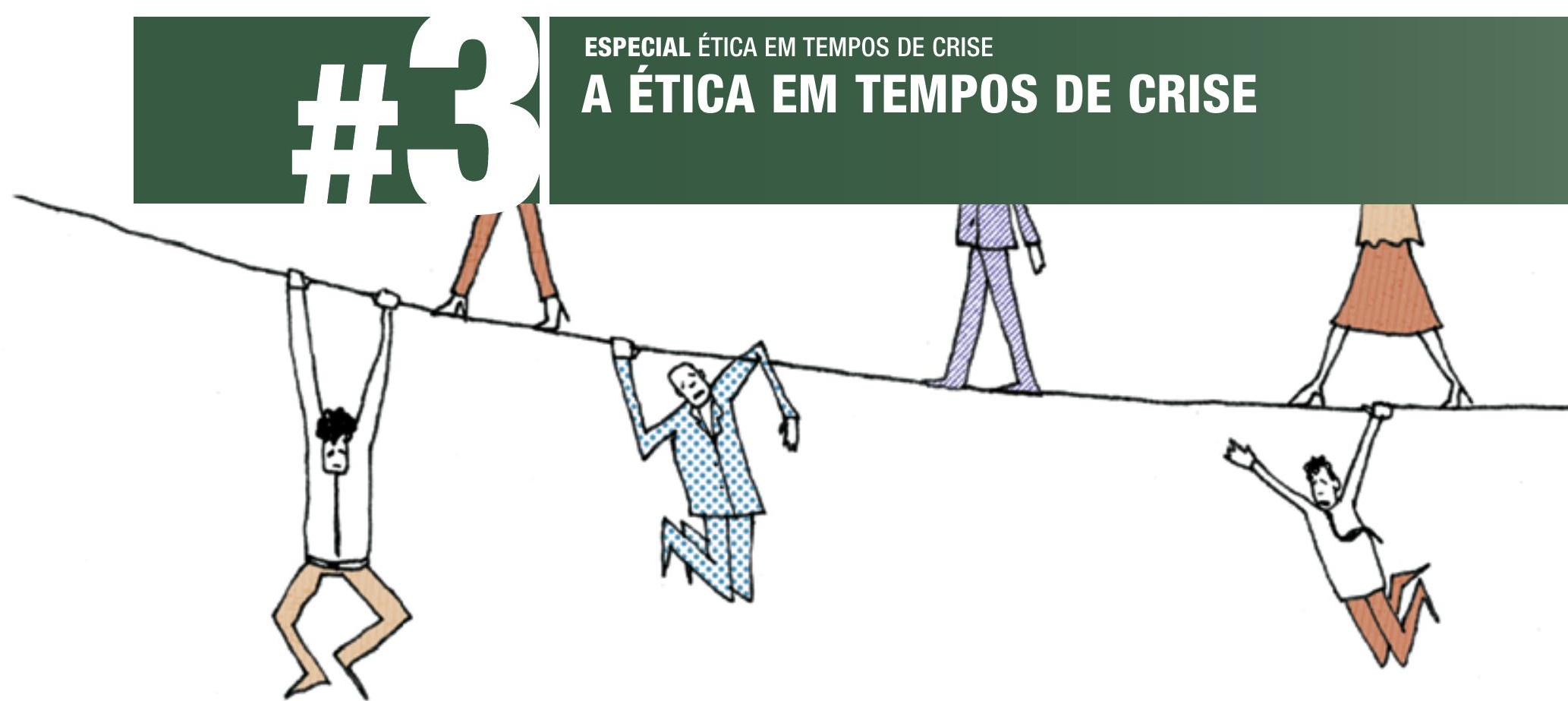

e do mundo, que desdiz da característica racional do ser humano. Convém lembrar que ainda há mais de um bilhão de pessoas sobrevivendo com pouco mais de um dólar por dia.

Sem dúvida, certas técnicas de marketing incrementam o consumo. Os líderes de opinião colaboram com as empresas nesse aspecto. O desafio dos empresários está justamente em possibilitar e incentivar o consumo, sem necessariamente transformar os consumidores em consumistas. A racionalidade no processo de compra deve ser estimulada por todos: famílias, governo, empresas, organizações não governamentais e outras instituições que prezem seriamente o bem-estar integral das pessoas.

\section{EQUILÍBRIO ECONÔMICO E MORAL}

Como solução, existe a proposta de estabelecer uma autoridade supranacional voltada à busca do bem comum universal, que orquestre o crescimento econômico, tanto dos países desenvolvidos como das nações ou áreas com grandes desigualdades sociais. Tal autoridade teria a função dinâmica de promover um desenvolvimento real, a defesa da vida e o crescimento cultural e moral das pessoas.

Essa transformação far-se-ia com a transferência de uma parte das atribuições nacionais para tal autoridade central ou correspondentes regionais, de modo gradual e equilibrado. Certamente ela se realizaria não sem angústias e sofrimentos, mas com decisão e magna- 


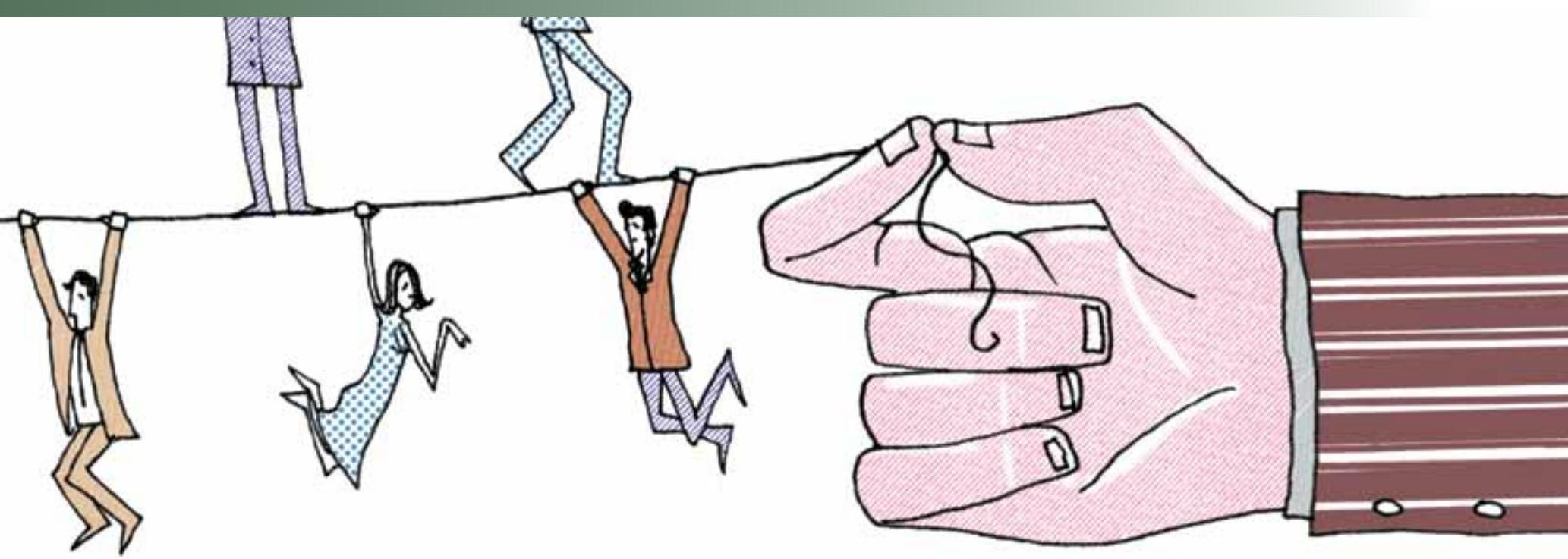

nimidade, com vistas ao desenvolvimento integral dos povos e de cada pessoa. Assim como a tecnologia e a globalização expandem e/ou excluem fronteiras, um organismo com vocação e competência mundiais, apoiado na prerrogativa e no dever de todos e para todos, sem discriminações, poderia assegurar a construção de uma sociedade comprometida com o bem comum e o próprio futuro. Seria a concretização da sustentabilidade, tão apregoada e ainda pouco efetiva.

O equilíbrio econômico facilita a convivência harmônica entre os cidadãos e entre os povos, mas isso não se dá apenas por meio do consumo de bens materiais. A transformação deve ocorrer antes, ou simultaneamente, no âmbito interior de cada pessoa. Seu desenvolvimento interior será a motivação para o maior rendimento no trabalho, para maior eficiência, para maior produtividade. Como consequência, sua remuneração tenderá a crescer e, com ela, virão mais tempo livre, mais descanso, mais tranquilidade, mais possibilidade de reflexão, melhor aproveitamento dos seus dons e talentos.

\section{RENOVAÇÃO NO AMBIENTE EMPRESARIAL}

O valor e a atividade da pessoa devem opor-se às forças que levam à massificação. O sentido de dignidade humana não pode ser perdido em nome do interesse econômico, seja do Estado coletivista, seja da iniciativa privada mal-intencionada ou mal controlada. A massificação pode afetar as pessoas, tanto por ações do governo como pela força da propaganda, por exemplo. Daí se compreende o surgimento de tantas associações de profissionais que desenvolvem códigos de autorregulamentação. O estabelecimento de limites éticos, por iniciativa dos próprios profissionais, deveria assegurar, de modo livre, o sentido de democracia, com respeito aos cidadãos.

A ética empresarial tem um papel fundamental nesse processo. O desenvolvimento tecnológico, o espírito de inovação e o marketing de produtos, serviços e ideias poderão contribuir para um novo sentido humano da vida. O crescimento econômico que respeite uma hierarquia moral, a ordem natural dos valores, possibilitará uma visão mais ampla e madura da cultura e do mundo. O capitalismo ético levará à busca do lucro com um espírito de construção de uma sociedade em que imperem a liberdade e a paz. A integridade norteará os empreendedores e governantes no sentido de assegurar uma convivência política, econômica e social dos povos e nações. 